\title{
WEAP modeling of surface water resources allocation in Didessa Sub-Basin, West Ethiopia
}

\author{
Tena Bekele Adgolign ${ }^{1}$ G. V. R. Srinivasa Rao ${ }^{1}$ ' Yerramsetty Abbulu ${ }^{1}$
}

Received: 8 May 2015/ Accepted: 26 November 2015/Published online: 14 December 2015

(C) Springer International Publishing Switzerland 2015

\begin{abstract}
The extensive water resources development plan that Ethiopia has recently embarked on encompasses all major river basins, including the Abbay Basin where Didessa Sub-basin is situated. The main objective of the study was to assess the impact of water resources development on instream and downstream water availability, and identify intra-sub-basin locations vulnerable to shortage of surface water, in Didessa Sub-basin. The Water Evaluation And Planning (WEAP) Tool was used to model the surface water resources allocation of the sub-basin, based on the water demand data extracted mainly from the Abbay Basin integrated development master plan. Existing demand sites were collected from irrigation and water supply sectors of the government. To estimate the crop water requirement and instream flows requirement (IFR), respectively CROPWAT 8.0 and Indicators of Hydrologic Alteration (IHA) programs were used. The shortage of recorded data of streamflow was supplemented by the outputs of SWAT hydrological model. Three development scenarios, viz., current development (2014), medium-term future development (2015-2030) and long-term future development (2031-2050), were built. It was demonstrated that the model sufficiently represented surface water flow of the sub-basin. The results indicated that at the last year
\end{abstract}

Tena Bekele Adgolign

tenabekele@yahoo.com

G. V. R. Srinivasa Rao

gvrsrao@gmail.com

Yerramsetty Abbulu

yabbulu@rediffmail.com

1 Department of Civil Engineering, College of Enginering (A), Andhra University, Visakhapatnam 530003, Andhra Pradesh, India of scenarios (2050), there will be a 1.101 billion cubic meters (BCM), i.e., $10.3 \%$, reduction in the total annual flow of Didessa River. Besides, it was found out that some of the schemes in Anger, Dabena and Upper Didessa watersheds will have unmet demands at the last year of scenarios. Nonetheless, it was shown that IFR of 5.46 BCM will be fully delivered at the outlet of Didessa River; hence, no sub-basin wide absolute scarcity of water would develop.

Keywords Demand site - Didessa sub-basin - IFR . Streamflow $\cdot$ Supply source $\cdot$ Unmet demand $\cdot$ WEAP

\section{Background}

Ethiopia has embarked on extensive water resources development plan since few years back. Though the development activities encompass all major river basins of the country, the huge agricultural and hydroelectric power potentials in the Abbay (Upper Blue Nile) Basin have attracted considerable attention. Hence, there are currently a number of water resources development projects in the construction and planning phases in Didessa Sub-basin of the Abbay Basin.

A water-stressed situation in a watershed does not occur instantaneously; rather, it is a phenomenon which develops through time. It has been a common practice to evaluate water crises after symptoms of water scarcity have begun to manifest themselves. It is, of course, very useful to make water allocation analysis even after water shortage has manifested itself, as it would lead to seeking a win-win situation among different water users (demand sites) in the watershed. However, assessing the overall water resources potentials and the existing and 
planned demand centers in the basin ahead of time would help in limiting developments only to the carrying capacity of the resource, while considering the sustainability issues which need to address the right of the future generation to make their lives from the resource.

The main objective of this study is to assess the impact of additional water demand and surface water resources development in Didessa Sub-basin on downstream and instream water availability, using the Water Evaluation And Planning (WEAP) system. Besides, vulnerable locations to shortage of water within the sub-basin due to water abstraction and use will be identified.

\section{Materials and methods}

\section{Location of the study area}

Didessa Sub-basin forms the southwestern protruding portion of Abbay Basin in West Ethiopia. The study area is situated between $07^{\circ} 42^{\prime} 40^{\prime \prime}-09^{\circ} 58^{\prime} 17^{\prime \prime}$ North latitude and $35^{\circ} 33^{\prime} 14^{\prime \prime}-37^{\circ} 07^{\prime} 52^{\prime \prime}$ East longitude. The total area of the watershed is about $28,092 \mathrm{~km}^{2}$. The major water resources development projects and demand sites to be input to the analysis are distributed on the main stem of Didessa River and along the four major tributaries, namely Anger, Dabena Wama and Upper Didessa rivers. Figure 1 shows location of Didessa Sub-basin.

\section{Dataset and data sources for Didessa Sub-basin WEAP model}

The major data types that are used in this study are hydrological time series data, water demand data, water supply schemes and their corresponding geographical locations, GIS vector map of Didessa Sub-basin and Didessa river system. Existing and planned projects have been included in the model.

McCartney and Girma (2012) witnessed the lack of information on water resources and the implications of different investment options had been a major challenge in the Abbay Basin. The condition in Didessa Sub-basin is even worse. Due to the lack of sufficient hydrological data (shortage of streamflow monitoring stations) at important points in the sub-basin, it was not possible to use recorded flow data in this model. Hence, an output of the SWAT hydrological model of the sub-basin, as suggested by (The Nature Conservancy 2009), has been used.

Table 1 summarizes the dataset used in WEAP modeling of the study area, and their corresponding sources.

\section{Demand sites and supply sources}

\section{Demand sites}

The demand sites and their corresponding annual activity levels have been identified from the Abbay Basin integrated development master plan project document and
Fig. 1 Location map of Didessa Sub-basin

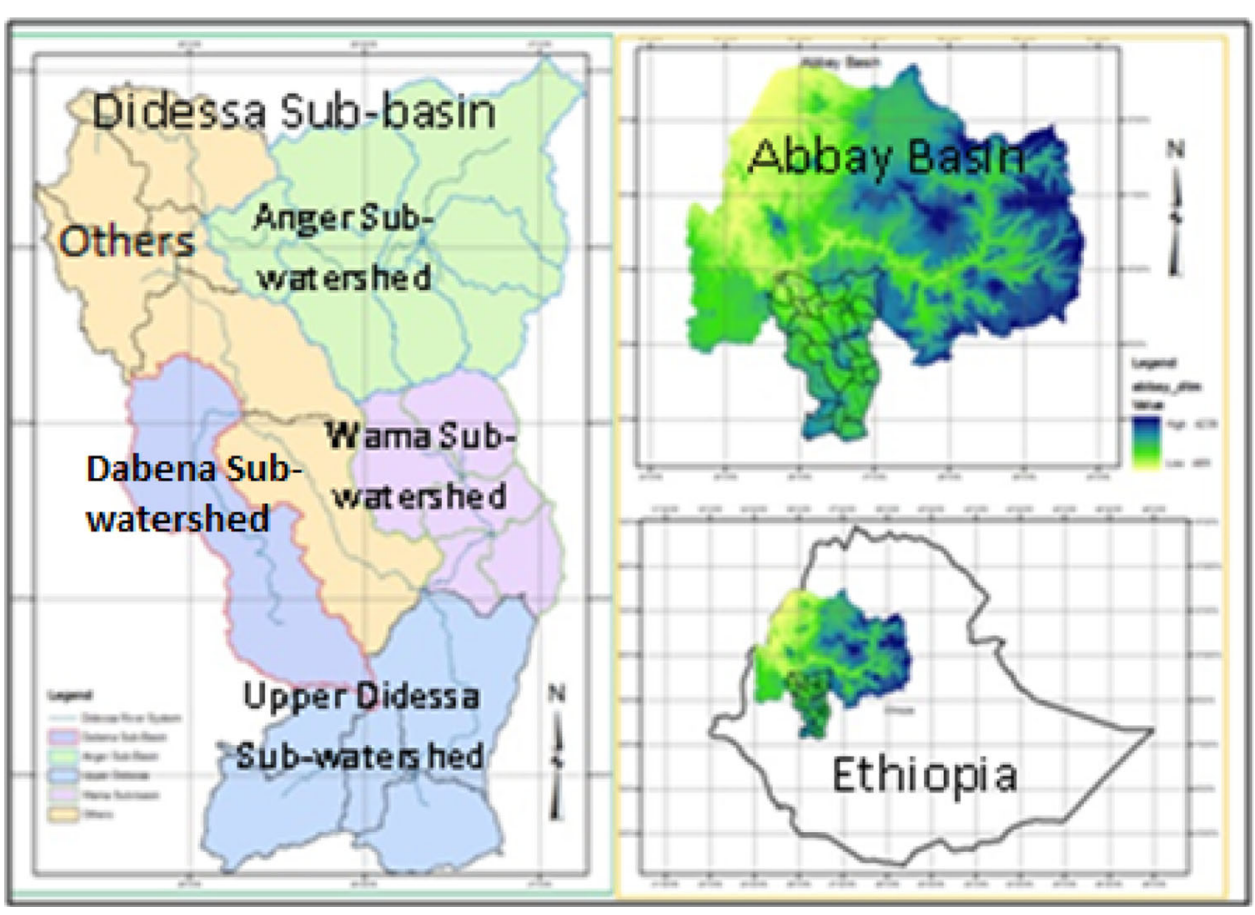


Table 1 Types and sources of input data for Didessa Sub-basin WEAP model

\begin{tabular}{|c|c|c|c|}
\hline Data type & Source & Scale/period & Description \\
\hline $\begin{array}{l}\text { Mean monthly } \\
\text { streamflow }\end{array}$ & Output of SWAT model & $\begin{array}{l}\text { Mean of } 31 \text { years } \\
(1982-2012)\end{array}$ & \\
\hline $\begin{array}{l}\text { Mean monthly } \\
\text { evapotranspiration }\end{array}$ & Ethiopian meteorological agency & $\begin{array}{l}\text { Mean of } 31 \text { years } \\
(1982-2012)\end{array}$ & \\
\hline $\begin{array}{l}\text { Demand sites and } \\
\text { supply sources }\end{array}$ & $\begin{array}{l}\text { Ministry of Water irrigation and energy } \\
\text { Oromia irrigation development authority } \\
\text { Nekemte and Bedele towns water supply and } \\
\text { sewerage authorities }\end{array}$ & & $\begin{array}{l}1998 \text { Abbay Basin integrated } \\
\text { development master plan } \\
\text { Existing irrigation development } \\
\text { schemes } \\
\text { Mean daily water supply }\end{array}$ \\
\hline
\end{tabular}

Table 2 Summary of existing and planned irrigation demand sites

\begin{tabular}{llcrr}
\hline Duration & \multicolumn{2}{l}{ Irrigable area (ha) } & Total \\
\cline { 2 - 3 } & Small-scale & Medium scale & Large scale & \\
\hline Base year (1998) & 3478 & & 3478 \\
Current development (2014) & 9196 & & & 9196 \\
Medium-term future development (2015-2030) & 22,241 & 1144 & 109,283 & 132,668 \\
Long-term future development (2031-2050) & 41,225 & 5227 & 143,418 & 189,870 \\
\hline
\end{tabular}

Oromia Irrigation Development Authority (OIDA). The major demand sites in the sub-basin are irrigation, domestic water and hydroelectric power demand sites. The irrigation schemes identified in the master plan amount to about 79,180 ha (MWR 1999). According to this document, small-scale irrigation (SSI) (less than $200 \mathrm{ha}$ ) potential in the sub-basin is more than 51,849 ha. However, the final and accurate location of the SSI schemes which would be implemented during the master plan period was not given. Hence, for the present study, the planned SSI schemes are located approximately. Table 2 shows the summary of irrigation development demand sites in the sub-basin, which have been identified to be implemented during the master plan period.

Besides, one hydroelectric power generating scheme, with an installed capacity of $300 \mathrm{MW}$ has been identified on the master plan.

The demand sites are distributed all over the sub-basin. Especially, as the areal extent of SSI schemes is small, and they are often managed at farm households' level, it is common to find them distributed along the majority of the small streams. Figure 2 shows the distribution of demand sites.

\section{Supply sources}

All supply sources of the existing and planned development in Didessa Sub-basin are fed from surface water resources of the main stem of Didessa River and its tributaries. The mean annual outflow from Didessa

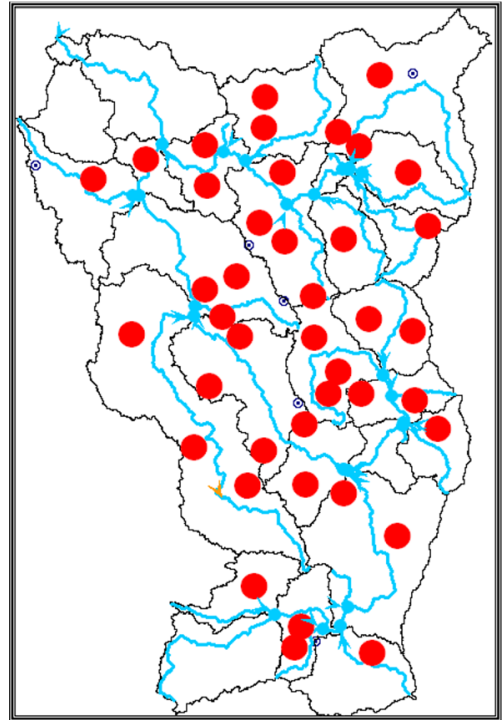

Fig. 2 Distribution of demand sites

River and its major tributaries is depicted on Table 3 below.

Currently, there are one reservoir and one pumping station as supply sources for domestic water supply for two urban areas in the sub-basin. One major dam and reservoir project, Arjo-Didessa Dam and Reservoir Project, is under construction, while four other dam and reservoir projects are encompassed in the medium and long-term development plans. The salient features of the supply sources are portrayed on Table 4 below. 
Table 3 Mean annual outflow of the major tributaries and the main stem of Didessa River

\begin{tabular}{llcc}
\hline Sr. no. & River & Catchment area $\left(\mathrm{km}^{2}\right)$ & Mean annual outflow $\left(\mathrm{BCM}^{*}\right)$ \\
\hline 1 & Anger & 7405 & 3.31 \\
2 & Dabena & 3341 & 1.22 \\
3 & Upper Didessa & 5540 & 1.98 \\
4 & Wama & 3372 & 1.51 \\
5 & Didessa (main stem) & 28,092 & 10.71 \\
\hline
\end{tabular}

Source: Tena et al. (2015)

$B C M *$ Billion cubic meters

\begin{tabular}{llllll}
\hline Sr. no. & Supply source & \multicolumn{2}{l}{ Location } & $\begin{array}{l}\text { Dam height } \\
(\mathrm{m})\end{array}$ & $\begin{array}{l}\text { Storage capacity } \\
\left(\mathrm{MCM}^{* *}\right)\end{array}$ \\
\cline { 3 - 5 } & Latitude $\left(^{\circ}\right)$ & Longitude $\left(^{\circ}\right)$ & & \\
\hline 1 & Arjo-Didessa reservoir & 8.525 & 36.664 & 47 & 1049.9 \\
2 & Anger reservoir & 9.692 & 36.74 & 80 & 1102 \\
3 & Nekemte reservoir & 9.431 & 36.499 & 30 & 71.5 \\
4 & Negesso reservoir & 8.859 & 36.547 & 30 & 104 \\
5 & Meka reservoir & 9.011 & 36.482 & 21 & 11 \\
6 & Bedele water supply & 8.436 & 36.245 & - & Pumping \\
7 & Lower Didessa reservoir & 9.486 & 35.985 & 78 & 5510 \\
\hline
\end{tabular}

Source: MWR (1999)

$M C M^{* *}$ Million cubic meters

\section{Annual water use rates}

I. Irrigation water demand:

Scarcity of weather monitoring stations, and short records in many of the existing stations is a challenge to the use of site specific crop water requirement estimation. Hence, the existing and planned schemes in the sub-basin were clustered into two categories depending on proximity and the agro-ecological similarity of the areas. Accordingly, two conventional meteorological stations with relatively better data availability, Bedele and Anger stations, were intentionally selected, as they are fairly representing the two agro-ecologic zoning of the existing and planned projects. It has been assumed that Bedele station, located at an altitude of $2011 \mathrm{~m}$ above sea level (m.a.s.l), and Anger station, located at an altitude of 1350 m.a.s.l, can, respectively, represent projects located in mid altitude (Woina Dega) and lowlands (Kolla) agro-climatic zones. The projects clustered under Anger Irrigation water demand scheme are found in the altitude range of about 1160-1500 m.a.s.l while those clustered under Bedele (Didessa) irrigation water demand scheme are found in altitude range of about 1500-1970 m.a.s.l. The other point that was considered as criteria for clustering was proximity of the areas to one another (adjacency of the sites). The clusters are:
A. Schemes located in Wama Watershed (Negesso Irrigation, small and medium scale irrigation schemes situated in Wama Watershed), schemes situated in Upper Didessa Watershed (Arjo-Didessa Irrigation, small and medium scale irrigation schemes situated in Upper Didessa Watershed and the upper reach of the main stem of Didessa River), and schemes situated in Dabena Watershed are categorized under Didessa irrigation water requirement scheme. To estimate the crop water requirement for this scheme, the meteorological parameters of Bedele Meteorological Station is used.

B. Schemes located in and around Anger Watershed (Anger Irrigation, Nekemte Irrigation, SSI schemes situated in Anger Watershed and schemes situated on the lower reach of the main stem of Didessa River) are categorized under Anger irrigation water requirement scheme.

The irrigation water demand has been estimated for a crop that requires the highest amount of water (sugarcane) as it is going to be grown widely, especially on ArjoDidessa Irrigation Development Project, the main objective of which is to develop sugarcane on 80,000 hectares of land. Sugarcane is considered to estimate the crop water requirement for the rest of the schemes, too, for two reasons. The first reason is that the freedom that small holder 
farm households have to select the type of crop to be grown would pose a challenge on determining the accurate type of crops grown and their corresponding areal extent; and the second is that the trend of organizing individual farmers as out-growers of sugarcane, that is being promoted in the former sugar factories, is expected to be practiced in the vicinity and nearby areas to Arjo-Didessa Sugar Factory as well.

Irrigation water demand was estimated using CROPWAT version 8.0, a programme developed by the Food and Agricultural Organization of the United Nations. The outputs of CROPWAT 8.0 (monthly irrigation requirements) for the two areal categories are summarized on Table 5.

\section{Domestic water demand:}

There are two major urban areas which have been deriving water from the tributaries of Didessa River for domestic use. Nekemte, the capital city of East Wollega Administrative Zone, is deriving water from a reservoir constructed on Meka Stream, and Bedele Town is deriving its water from Dabena River. The World Health Organization (WHO) recommends about 1001 of water per person per day to ensure that most basic needs are met and few health concerns arise (WHO 2003). On the other hand the water supply authorities of the two towns claim that they are distributing 4095 and $8400 \mathrm{~m}^{3} /$ day for Bedele and Nekemte, respectively. For this study, per capita water supply of 1001 per day $\left(36.5 \mathrm{~m}^{3} /\right.$ cap/year $)$ is used.

\section{Instream (environmental) flows requirement:}

Environmental flows is required in order to protect natural reserves and preserve the ecosystems. The ever increasing recognition of environmental flows as vital in maintaining healthy, productive and sustainable river and groundwater systems deserves the attention of all actors. That is, the arbitration in the competition for water between different users, including the environment, should go beyond being the duty of certain institutions or environmental activists. As physical water scarcity is said to occur when there is not enough water to meet all demands, including environmental flows, the environment need to be allocated its fair share of water (FAO 2012). The allocation of water for instream flow requirement right before the symptoms of physical water scarcity like severe environmental degradation, declining groundwater, and water allocations that favor some groups over others, manifests, would help minimize the unfavorable effects occurring as a result of shortage of water.

Hence, environmental flows is one of the various water demands that need to be incorporated in water resources allocation modeling. Current aquatic ecology and empirical observations suggest that a hydrological regime characterized by the full or nearly full range of natural variation is necessary to sustain the full native biodiversity and integrity of aquatic ecosystems (Richter et al. 1997).

Quantifying the ecological reserve for rivers involves determining the water quantity and quality requirements that will ensure that they are sustained in a pre-determined condition. This condition can vary from largely natural to largely modified where there is a large loss of natural habitat, biota and basic ecosystem functioning (Hughes and Hannart 2003). It is, therefore, recognized that while some rivers are environmentally important, the requirements for socio-economic development in a water scarce country
Table 5 Summary of irrigation requirements for the two stations

\begin{tabular}{|c|c|c|c|c|c|c|}
\hline \multirow[t]{3}{*}{ Month } & \multicolumn{6}{|c|}{ Station } \\
\hline & \multicolumn{3}{|l|}{ Anger } & \multicolumn{3}{|c|}{ Didessa } \\
\hline & $\mathrm{mm}$ & $\mathrm{m}^{3} / \mathrm{ha}$ & Monthly variation (\%) & $\mathrm{mm}$ & $\mathrm{m}^{3} / \mathrm{ha}$ & Monthly variation (\%) \\
\hline January & 48.7 & 487 & 6.37 & 96.1 & 961 & 19.66 \\
\hline February & 73.5 & 735 & 9.61 & 99.1 & 991 & 20.28 \\
\hline March & 130.8 & 1308 & 17.10 & 80.5 & 805 & 16.47 \\
\hline April & 175.9 & 1759 & 23.00 & 43.0 & 430 & 8.80 \\
\hline May & 151.0 & 1510 & 19.75 & 47.6 & 476 & 9.74 \\
\hline June & 68.5 & 685 & 8.96 & 6.6 & 66 & 1.35 \\
\hline July & 9.1 & 91 & 1.19 & 0 & 0 & 0 \\
\hline August & 0.0 & 0 & 0 & 0 & 0 & 0 \\
\hline September & 2.8 & 28 & 0.37 & 0 & 0 & 0 \\
\hline October & 0.0 & 0 & 0 & 0 & 0 & 0 \\
\hline November & 23.3 & 233 & 3.05 & 24.2 & 242 & 4.95 \\
\hline December & 81.1 & 811 & 10.61 & 91.6 & 916 & 18.74 \\
\hline Total & 764.7 & 7647 & 100.00 & 488.7 & 4887 & 100.00 \\
\hline
\end{tabular}

Crop type: sugarcane 
Table 6 Annual streamflow and instream flow requirements at some important reaches

\begin{tabular}{lllll}
\hline Sr. no. & Subbasin/Reach Name & Streamflow $(\mathrm{BCM})$ & IFR (BCM) & Remark \\
\hline 1 & Anger-5 & 0.78 & 0.47 & D/s of Anger reservoir \\
2 & Anger-13 & 2.48 & 1.52 & D/s of Nekemte reservoir \\
3 & Anger-7 & 3.31 & 2.13 & Outlet of Anger river \\
4 & Dabena-24 & 1.22 & 0.73 & Outlet of Dabena river \\
5 & Upper Didessa-23 & 1.98 & 0.90 & D/s of Arjo-Didessa reservoir; outlet of Upper Didessa river \\
6 & Wama-17 & 0.36 & 0.18 & D/s of Negesso reservoir \\
7 & Wama-21 & 1.51 & 0.97 & Outlet of Wama river \\
8 & Didessa-Nr. Arjo & 3.90 & 2.41 & Gauging station \\
9 & Didessa-15 & 6.41 & 3.33 & D/s of Dabena's confluence with Didessa \\
10 & Didessa-9 & 6.63 & 3.57 & U/s of Anger's confluence with Didessa \\
11 & Didessa Main-1 & 10.71 & 5.46 & Outlet of Didessa main \\
\hline
\end{tabular}

Source for streamflow: Tena et al. (2015)

suggest that not all rivers can be retained in a near natural state. It is also recognized that resource development should be environmentally sustainable and therefore all rivers should retain some basic ecological functioning.

According to Smakhtin et al. (2006), the desktop environmental flows assessment (EFA) methods are more suitable for initial, reconnaissance-level assessments of environmental flows requirements in unregulated river basins and/or river basins where the pressure on water resources is not yet extreme, but starting to grow. Didessa Sub-basin falls under this category of rivers; hence, the method is appropriate at this level to make initial estimates of EFA. Notwithstanding the importance of obtaining a well refined environmental flows estimates based on ecological and livelihood studies, data scarcity and the fact that hydroecological surveys have rarely been conducted in the sub-basin would compel one to use the desktop model, at least at this initial stage.

The Indicators of Hydrologic Alteration (IHA) calculates parameters for five different types of environment flow components (EFCs): low flows, extreme low flows, high flow pulses, small floods, and large floods. This delineation of EFCs is based on the realization by research ecologists that river hydrographs can be divided into a repeating set of hydrographic patterns that are ecologically relevant. It is the full spectrum of flow conditions represented by these five types of flow events that must be maintained in order to sustain riverine ecological integrity. Not only is it essential to maintain adequate flows during low flow periods, but higher flows and floods and also extreme low flow conditions also perform important ecological functions (The Nature Conservancy 2009).

The low flows is the dominant flow condition in most rivers. In natural rivers, after a rainfall event or snowmelt period has passed and associated surface runoff from the catchment has subsided, the river returns to its base- or low-flow level. These low-flow levels are sustained by groundwater discharge into the river. The seasonallyvarying low-flow levels in a river impose a fundamental constraint on a river's aquatic communities because it determines the amount of aquatic habitat available for most of the year. This has a strong influence on the diversity and number of organisms that can live in the river (The Nature Conservancy 2009).

Thus, the low flows parameter of the IHA's environmental flows component satisfies the environmental water demand (instream flow requirements) of rivers. Hence, for Didessa Sub-basin, the instream flow requirements at the downstream of the major reservoirs, at the outlet of the four major tributaries and the outlet of Didessa River have been determined using the IHA. The mean annual outflow and instream flow requirements for some important reaches are shown on Table 6.

Figure 3 shows location of points where IFR are determined.

\section{The WEAP model}

\section{Background}

The Water Evaluation And Planning version 21 (WEAP21) integrated water resource management (IWRM) model seamlessly integrates water supplies generated through watershed-scale hydrologic processes with a water management model driven by water demands and environmental requirements and is governed by the natural watershed and physical network of reservoirs, canals, and diversions (Yates et al. 2005). WEAP is a PC based surface and groundwater resource simulation tool, based on water balance accounting principles, which can test alternative 


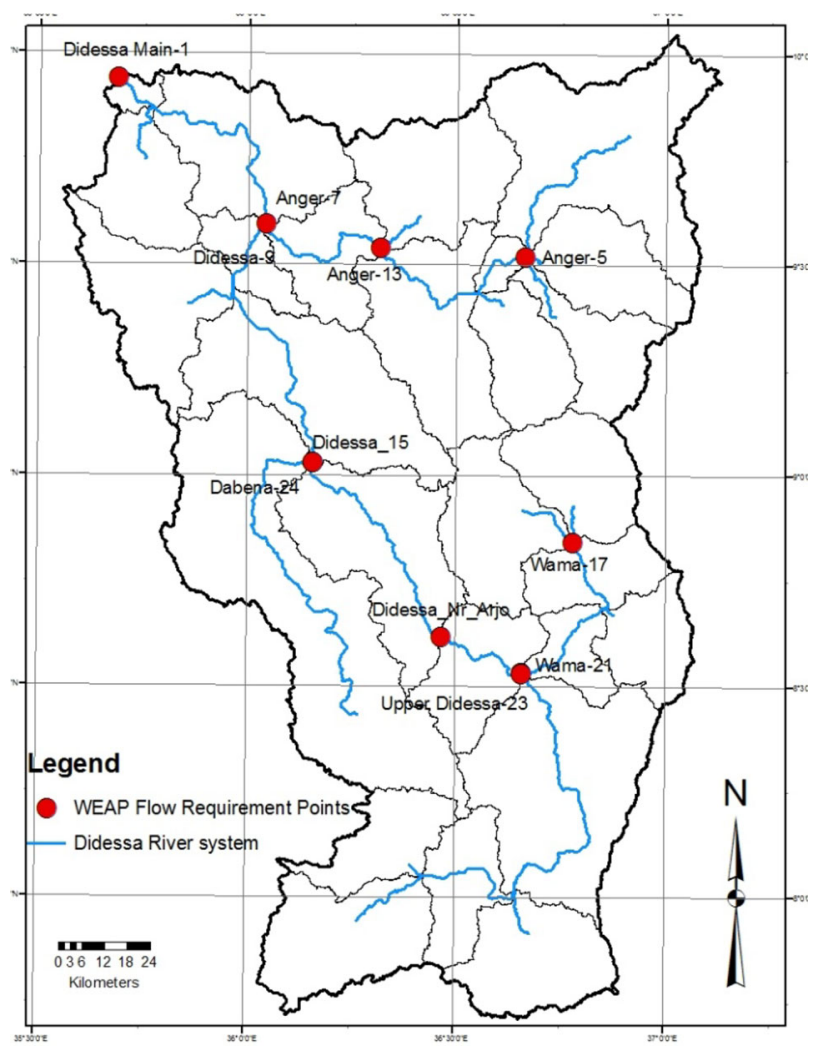

Fig. 3 Location of WEAP IFR points

sets of conditions of both supply and demand. The change in water demand, supply and pollution can be projected over a long-term planning horizon to develop adaptive management strategies.

WEAP has been used in several water related researches/ projects across the world. For example WEAP was used to determine the likely impact of a number of possible development scenarios in Lake Tana Catchment, Ethiopia, on lake water levels (Alemayehu et al. 2010). It was also used to evaluate Ethiopia's policy of large dam construction in the Blue Nile River basin by simulating the impact of one downscaled midrange climate change scenario (A1B) on the performance of existing and planned hydropower and irrigation schemes (McCartney and Girma 2012).

WEAP is widely used in other parts of the world, too. For example, Arranz and McCartney (2007) applied WEAP Model to assess future water demands and resources in the Olifants Catchment, South Africa. Mounir et al. (2011) also conducted a study using WEAP model to investigate scenarios of future water resource development in the Niger River Basin in Niger Republic. Similarly, it was used to assess the potential effects of climate change and adaptive management on irrigation water supply in the Cache Creek watershed in California (Mehta et al. 2013). Hence, WEAP model has high global popularity in scenario analyses of water demands and supplies.
In the present study, WEAP21 is used to evaluate the implications of existing and planned water resources development in Didessa Sub-basin, on instream and downstream water availability.

\section{Model setup}

Modeling assumptions Regardless of the differences in financial returns expected from each scheme, all demand sites were designated equal priority in water provision. Hence, recognizing the environment as a legitimate user of water, it was also designated equal priority to the other demand sites. With the exception of Arjo-Didessa Dam which is currently under construction, and is expected to be commissioned in 2015, all major dams listed in the Abbay Basin integrated development master plan corresponding to Didessa Sub-basin are at the planning stage. Hence, operating rule curves are currently not available for anyone of them, and none is incorporated in the WEAP model of the sub-basin.

The other important assumption to be noted is that the annual water use rate for agriculture (irrigation) is estimated for sugarcane, a crop which will be widely grown, and which has, relatively, higher crop water demand.

\section{Development scenarios}

WIKIPEDIA-The Free Encyclopedia defines Scenario analysis as "a process of analyzing possible future events by considering alternative possible outcomes (sometimes called "alternative worlds")" (WIKIPEDIA 2015). Accordingly, the scenario analysis, which is a main method of projections, does not try to show one exact picture of the future. Instead, it presents consciously several alternative future developments. Consequently, a scope of possible future outcomes is observable.

In a way more relevant to water resources, scenarios are defined as alternative sets of assumptions such as different operating policies, costs, and factors that affect demand such as demand management strategies, alternative supply sources and hydrologic assumptions, with changes in these data able to grow or decline at varying rates over the planning horizon of the study. Thus, scenarios are not created from the minds of the requirements engineers; their definition should be anchored on real situations (Leite et al. 2000). The typical characteristic of this (scenario analysis) method is that it can model many real problems where decisions are based on uncertain information presented as a set of possible outcomes (i.e., scenarios) (Weng et al. 2010).

The Abbay River Basin integrated development master plan MWR (1999) has been the basis to build development scenarios for the present study. The master plan was formulated in 1998, for a time horizon of 50 years. Hence, the 
years 1998 and 2050 are, respectively, considered as the current accounts year and last year of scenarios.

Assuming different growth rates, two scenarios were formulated on the Abbay Basin integrated development master plan, as to when to implement the planned projects: conservative scenario and accelerated scenario (MWR 1999). The development periods were classified as 1999-2014, 2015-2030 and 2031-2050. However, it was observed that most of the schemes proposed on the master plan have not yet been constructed except a few SSI schemes. Hence, the existing developments are directly translated into base year and current accounts scenario, and a minor adjustment has been made on the implementation timing of the planned developments without significant change in the current accounts year, intermediate years and last year of scenarios. Major projects whose start up years have not yet elapsed are maintained as per their initial schedules as long as they are not preceded by a project whose start up period has passed.

Three development scenarios, namely reference (current development) (1999-2014), medium-term future development (2015-2030) and long-term future development (2031-2050) scenarios have been proposed.

Regarding the developments which were undertaken during the reference scenario time horizon, additional inputs from irrigation development and water supply sectors have been incorporated. As McCartney and Girma (2012) observed, Ethiopia has utilized very little of the Blue Nile water due to physical, infrastructural, socioeconomic, etc., constraints. This is particularly true when Didessa River is considered. So far, only few SSI schemes and no hydropower development exist in Didessa Subbasin. Table 7 portrays the major demand sites and their corresponding annual activity levels in the sub-basin.

Table 7 Scenario building

\begin{tabular}{|c|c|c|c|c|c|c|}
\hline \multirow{2}{*}{$\begin{array}{l}\text { Sr. } \\
\text { no. }\end{array}$} & \multirow[t]{2}{*}{ Description } & \multicolumn{4}{|l|}{ Scenarios } & \\
\hline & & Base Year (1998) & $\begin{array}{l}\text { Reference (current } \\
\text { development) } \\
(1999-2014)\end{array}$ & $\begin{array}{l}\text { Medium-term future } \\
\text { development } \\
(2015-2030)\end{array}$ & $\begin{array}{l}\text { Long-term future } \\
\text { development } \\
(2031-2050)\end{array}$ & \\
\hline \multirow{3}{*}{$\begin{array}{l}\text { A } \\
\text { A. } 1\end{array}$} & \multicolumn{6}{|c|}{ Domestic water demand (MCM/year at the end of scenario period) } \\
\hline & $\begin{array}{l}\text { Nekemte town domestic } \\
\text { water demand }\end{array}$ & 1.93 & 3.67 & 6.97 & 15.57 & \\
\hline & A. 2 & $\begin{array}{l}\text { Bedele town } \\
\text { domestic water } \\
\text { demand }\end{array}$ & 0.50 & 0.95 & 1.81 & 4.04 \\
\hline B & \multicolumn{6}{|c|}{ Agricultural (irrigation) activity levels (ha) } \\
\hline B. 1 & EW-SSI & 3161 & 8079 & 19,903 & 37,951 & \\
\hline B. 2 & WW-SSI & 80 & 80 & 80 & 80 & \\
\hline B. 3 & IAB-SSI & 201 & 401 & 822 & 822 & \\
\hline B. 4 & Jima-SSI & 36 & 636 & 1436 & 2372 & \\
\hline B. 5 & Arjo-Didessa irrigation & - & - & 80,000 & 80,000 & \\
\hline B.6 & Anger irrigation & - & - & 8000 & 14,450 & \\
\hline B.7 & Nekemte irrigation & - & - & 6000 & 11,220 & \\
\hline B. 8 & Negesso irrigation & - & - & 5000 & 21,315 & \\
\hline B.9 & Hida irrigation & - & - & 5650 & 5650 & \\
\hline B. 10 & Wama irrigation & - & - & 325 & 325 & \\
\hline B. 11 & Lugo irrigation & - & - & 285 & 285 & \\
\hline B. 12 & Dimtu and Didiga irrigation & - & - & 5167 & 5167 & \\
\hline B. 13 & Upper Dabena irrigation & - & - & - & 1150 & \\
\hline \multirow[t]{2}{*}{ B. 14} & Dabena irrigation & - & - & - & 6150 & \\
\hline & B.15 & Urgessa irrigation & - & - & - & 2933 \\
\hline $\mathrm{C}$ & \multicolumn{5}{|c|}{ Hydropower activity level (GWH) } & \\
\hline C. 1 & $\begin{array}{l}\text { Lower Didessa hydropower } \\
\text { ( } 300 \text { MW installed } \\
\text { capacity) }\end{array}$ & - & - & - & 1582 & \\
\hline D & $\begin{array}{l}\text { Environmental flows } \\
\text { requirement }\end{array}$ & $\sqrt{ }$ & $\sqrt{ }$ & $\sqrt{ }$ & $\sqrt{ }$ & \\
\hline
\end{tabular}

Data source: MWR (1999), OIDA (2014) 


\section{Schematic of the study area}

A schematic, or schematic diagram, is a representation of the elements of a system using abstract, graphic symbols rather than realistic pictures. A schematic usually omits all details that are not relevant to the information the schematic is intended to convey, and may add unrealistic elements that aid comprehension (WIKIPEDIA 2015). The Schematic View is the starting point for all activities in WEAP (SEI 2011).

WEAP allows the display of GIS layers as overlays or backgrounds on the WEAP Schematic. Hence, Didessa Sub-basin vector layer, which includes Didessa River system, has been added. An image of the WEAP schematic is shown below (Fig. 4).

The existing and planned development in the sub-basin during the three development scenarios have been summarized on the following figures (Fig. 5).

The monthly headflows data were obtained from the SWAT Hydrological Model of the Sub-basin (Tena et al. 2015) and entered into the headflows environment for each stream. Similarly, the data for all demand sites, supply and resources, key assumptions, etc. were entered.

\section{Results and discussion}

The WEAP model performs a mass balance of flow sequentially down a river system, making allowances for abstractions/water use and inflows. The elements that comprise the water demand-supply system and their spatial relationship are characterized within the model. The WEAP model for Didessa River system was setup to simulate the base year (1998) situation and three subsequent scenarios: the Reference (current) situation (1999-2014), the Mediumterm future development (2015-2030), and the long-term future development (2031-2050) scenarios. The basis for the timelines of these scenarios is the Abbay Basin integrated development master plan of 1998.

For each scenario, the main outputs analyzed include the extent of satisfying the water demand of different sectors, the degree to which the instream flow requirements is satisfied, and the spatial and temporal variation in water shortages, if any. Due consideration was rendered to determining the streamflow at the catchment outlets and the outlet of the main stem of Didessa River so as to determine the cumulative impact of additional upstream water abstraction on instream and downstream water availability.

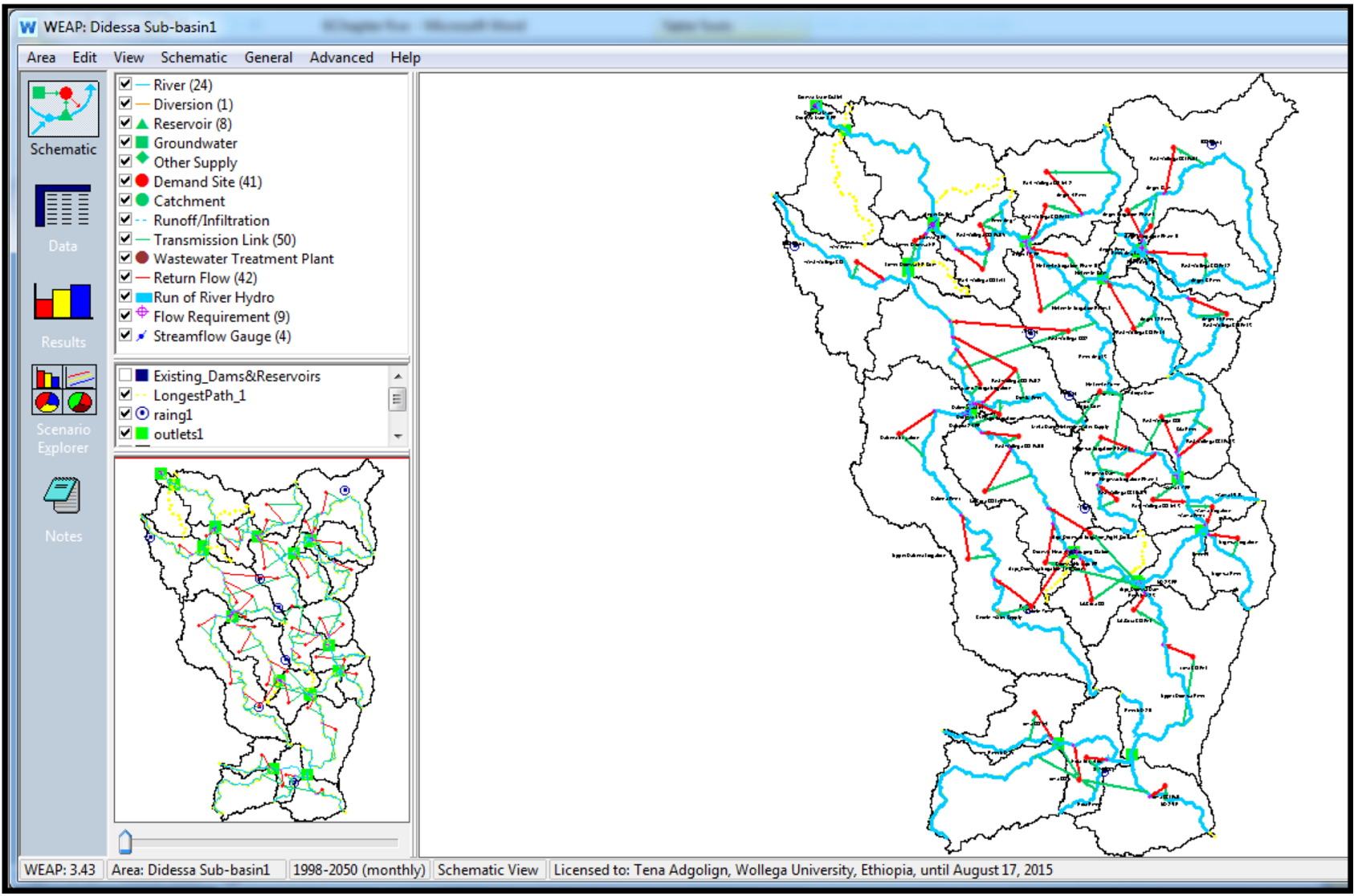

Fig. 4 Screenshot of the schematic of Didessa Sub-basin WEAP model 


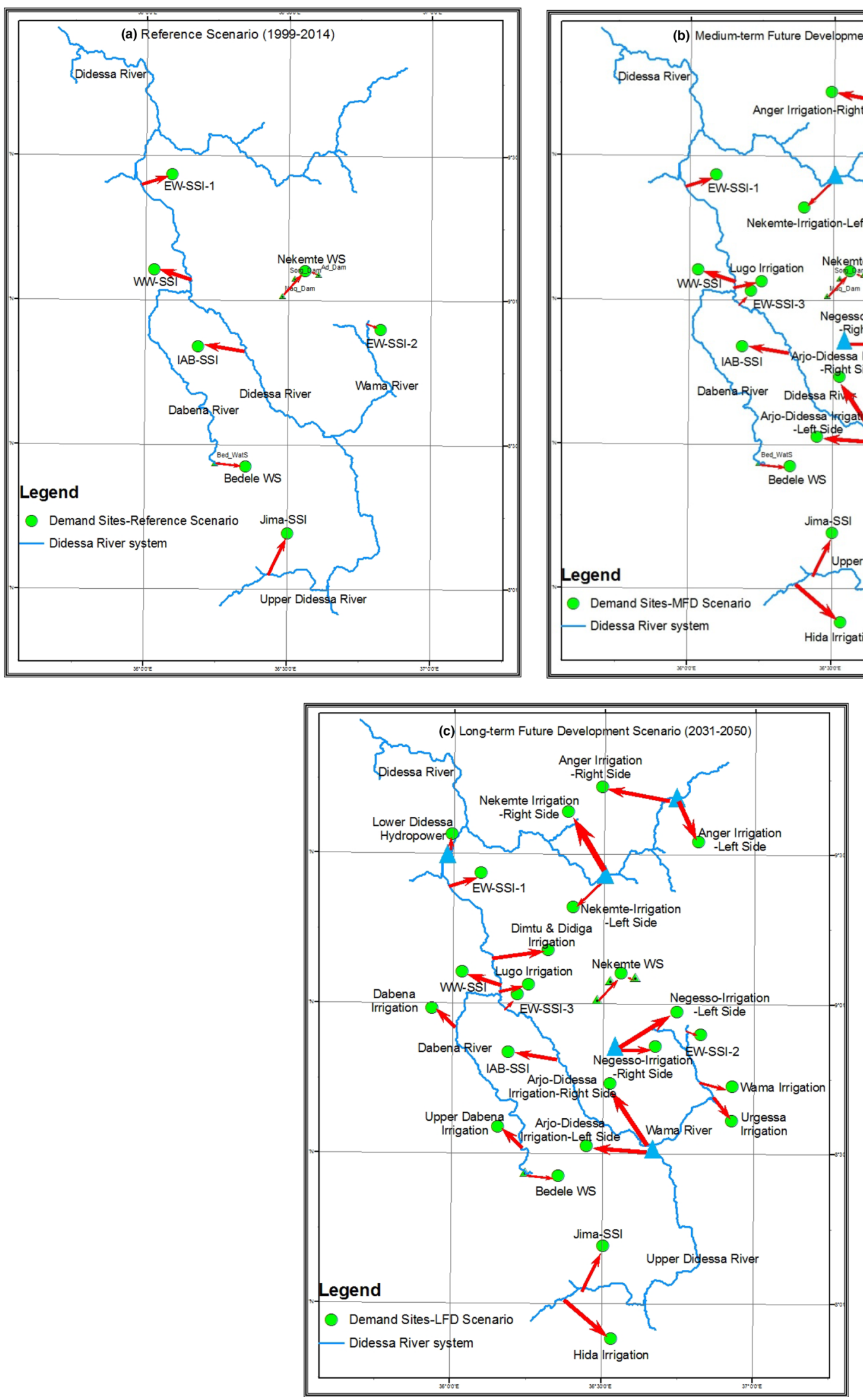

Fig. 5 Line representation (schematic) of the model for different development scenarios 


\section{Water demand, streamflow and instream flow requirements (IFR)}

The total annual water demand under the three development scenarios is depicted on Table 8 below.

The annual streamflow of the main stem of Didessa River and the four major tributaries as per the WEAP model of the sub-basin, for the three development scenarios are depicted below (Fig. 6).

From the SWAT hydrologic model of the sub-basin, the mean annual flowout at Didessa-Abbay confluence is 10.71 BCM (Tena et al. 2015). This value is sufficiently comparable with WEAP's 10.63 BCM for the reference scenario. The SWAT hydrologic modeling of Didessa Subbasin involved setting up the model using a DEM of $20 \mathrm{~m}$ horizontal resolution, land use/cover and soils maps obtained from the Ministry of Water, Irrigation and
Energy. Weather data from selected weather monitoring stations were used to setup the model.

The model calibration and validation were performed using the sequential uncertainty fitting (SUFI-2) algorithm of SWAT calibration and uncertainty programs (SWATCUP). The model predicted monthly discharge with high accuracy, with Nash Sutcliff Efficiency (NSE) values of 0.87 and 0.80 for the calibration (1982-1986) and validation (1992-1996) periods, respectively; and coefficient of determination $\left(R^{2}\right)$ values of 0.87 and 0.80 for the calibration and validation periods, respectively. The calibration and validation of the model were performed for a measured flow data at Didessa Near Arjo gauging station, which is located at $8^{\circ} 4^{\prime} \mathrm{N}$ latitude and $36^{\circ} 25^{\prime}$ E longitude.

The following chart (Fig. 7) depicts the temporal and spatial distribution of streamflow at the end of the longterm future development scenario. The streamflow for the
Table 8 Total annual water demand under the three development scenarios

Fig. 6 Annual streamflow under each scenario (output of WEAP model)

Fig. 7 Monthly streamflow at the end of Long-term future development scenario

\begin{tabular}{lcc}
\hline Scenario & Demand $(\mathrm{MCM})$ & \% of the mean annual streamflow \\
\hline Reference & 74.72 & 0.70 \\
Medium-term Future & 746.22 & 6.97 \\
Long-term Future & 1199.33 & 11.20 \\
\hline
\end{tabular}

\begin{tabular}{|c|c|c|c|c|c|c|}
\hline \multicolumn{7}{|c|}{ Mean annual stremflow of Didessa River and the major tributaries } \\
\hline \multirow{6}{*}{ 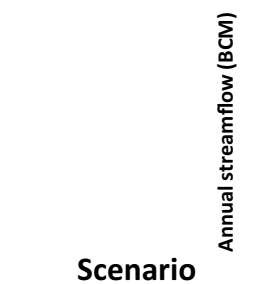 } & \multirow{6}{*}{$\begin{array}{r}12.000 \\
10.000 \\
8.000 \\
6.000 \\
4.000 \\
2.000 \\
0.000\end{array}$} & & & & & \\
\hline & & & & & & \\
\hline & & & & & & \\
\hline & & & & & & \\
\hline & & & & & & \\
\hline & & Anger & Dabena & Upper & Wama & Didessa \\
\hline \multicolumn{2}{|l|}{ Reference } & 3.243 & 1.219 & 1.977 & 1.487 & 10.632 \\
\hline \multicolumn{2}{|l|}{$\begin{array}{l}\text { Medium-term Future } \\
\text { Development }\end{array}$} & 3.049 & 1.218 & 1.537 & 1.474 & 10.016 \\
\hline \multicolumn{2}{|c|}{ Long-term Future Development } & 2.928 & 1.189 & 1.533 & 1.430 & 9.609 \\
\hline
\end{tabular}

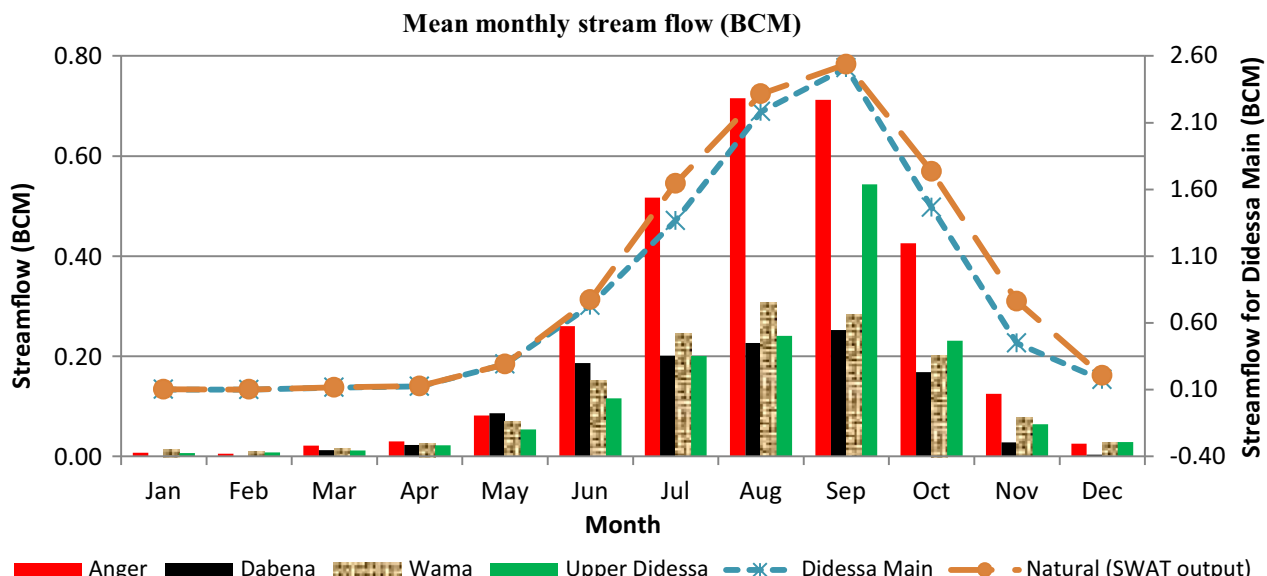




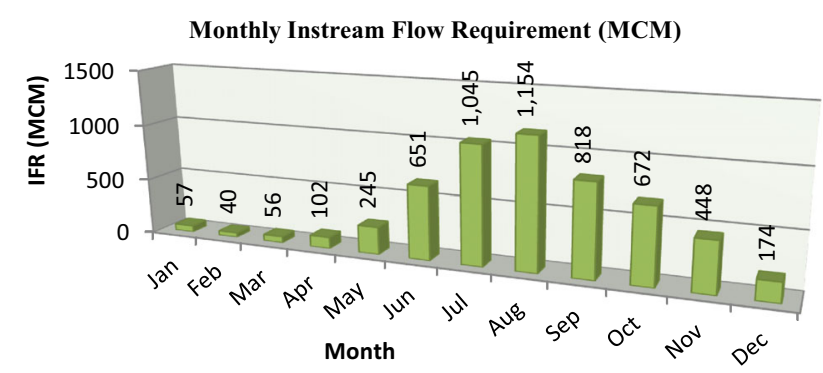

Fig. 8 Monthly IFR for Didessa River at Didessa-Abbay confluence (2050)

main stem of Didessa River according to SWAT Hydrologic Model ('natural') has been added for comparison. In WEAP, natural flow is meant to indicate the river flow without any development. Besides, the outputs of the SWAT model for the major tributaries and main stem of Didessa River at its outlet have been considered as natural flow, as there is no flow monitoring station towards the downstream ends of the rivers to get recoded flow data and make analyses of water consumption and instream flow requirement. The word natural has been put in single quotation mark ('natural') to make a distinction that the flow is not a recorded natural flow.

The streamflow data for the tributaries is also reasonably comparable to those obtained from the SWAT hydrologic model.

The monthly Instream Flow Requirement for the main stem of Didessa River at the end of the long-term future development scenario is depicted below (Fig. 8). The chart shows that the Instream Flow Requirement varies in a similar trend with the monthly streamflow.

Table 9 shows streamflow, IFR, and IFR delivered at some important reaches of the main stem of Didessa River and its tributaries. It can be observed from the table that except Dabena River, the IFR has been satisfied in the mentioned reaches. It seems that the flow of Dabena River cannot satisfy the urban, agricultural and environmental water needs of the currently existing demand sites (Bedele Town Water Supply) and the plan to be implemented until 2050.

\section{Change in streamflow and water consumption}

The existing and planned development will cause some changes in river flow of the tributaries and the main stem of Didessa River. Table 10 summarizes streamflow for the current development and the two future development scenarios.

Table 10 portrays the mean annual streamflow across scenarios. It shows that at the end of the long-term future development scenario, the annual flow of Didessa River will decrease to $9.609 \mathrm{BCM}$. This shows that the water consumed by demand sites will be $1.101 \mathrm{BCM}(10.3 \%$ of the mean annual flow). Table 10 shows the water consumption details for the main stem and the four major tributaries of Didessa River.

\section{Spatial and temporal occurrence of water shortage/ Unmet demands under each scenario}

\section{Spatial (Watershed-wise) occurrence of unmet demand}

The spatial occurrence of unmet demands across the watersheds is shown bellow (Table 11).

As shown above, there is unmet demand in all watersheds particularly for the medium-term and long-term future development scenarios, although there is variation in the extent of shortage. In this regard, Wama Watershed is in a better condition.

\section{Spatial (Demand site-wise) occurrence of unmet demand}

Demand sites with unmet water demand and their corresponding unmet demands are portrayed on Fig. 9 below.

Table 9 Annual streamflow and instream flow requirements for some important reaches

\begin{tabular}{|c|c|c|c|c|c|}
\hline Sr. no. & Subbasin/reach name & Streamflow (BCM) & IFR (BCM) & IFR delivered (BCM) & Remarks \\
\hline 1 & Anger-5 & 0.78 & 0.47 & 0.47 & \\
\hline 2 & Anger-13 & 2.48 & 1.52 & 1.52 & \\
\hline 3 & Anger-7 & 3.31 & 2.13 & 2.13 & Outlet of Anger R. \\
\hline 4 & Dabena-24 & 1.22 & 0.724 & 0.703 & Unmet IFR $=0.021$ \\
\hline 5 & Upper Didessa-23 & 1.98 & 0.90 & 0.90 & Outlet of Wama R. \\
\hline 6 & Wama-17 & 0.36 & 0.177 & 0.177 & \\
\hline 7 & Wama-21 & 1.51 & 0.975 & 0.975 & Outlet of U/Didessa R \\
\hline 8 & Didessa- Nr. Arjo & 3.90 & 2.405 & 2.405 & \\
\hline 9 & Didessa-15 & 6.41 & 3.568 & 3.568 & \\
\hline 10 & Didessa-9 & 6.63 & 3.326 & 3.326 & \\
\hline 11 & Didessa Main-1 & 10.71 & 5.463 & 5.463 & Outlet of Didessa R. \\
\hline
\end{tabular}


Table 10 Changes in river flow under each scenario for the major tributaries and the main stem of Didessa River

\begin{tabular}{|c|c|c|c|c|c|c|c|c|c|}
\hline \multirow{2}{*}{$\begin{array}{l}\text { Sr. } \\
\text { no. }\end{array}$} & \multirow[t]{2}{*}{ River } & \multirow{2}{*}{\multicolumn{2}{|c|}{$\begin{array}{l}\text { 'Natural' (output of SWAT } \\
\text { model) }\end{array}$}} & \multicolumn{6}{|c|}{ Annual stream flow under each scenario (BCM) } \\
\hline & & & & \multicolumn{2}{|c|}{$\begin{array}{l}\text { Current } \\
\text { development }\end{array}$} & \multicolumn{2}{|c|}{$\begin{array}{l}\text { Medium-term future } \\
\text { development }\end{array}$} & \multicolumn{2}{|l|}{$\begin{array}{l}\text { Long-term future } \\
\text { development }\end{array}$} \\
\hline \multicolumn{10}{|c|}{ a. Mean annual streamflow across scenarios } \\
\hline 1 & Anger & 3.31 & \multicolumn{3}{|c|}{3.243} & \multicolumn{2}{|l|}{3.049} & \multicolumn{2}{|l|}{2.928} \\
\hline 2 & Dabena & 1.22 & \multicolumn{3}{|c|}{1.219} & \multicolumn{2}{|l|}{1.218} & \multicolumn{2}{|l|}{1.189} \\
\hline 3 & Wama & 1.51 & \multicolumn{3}{|c|}{1.487} & \multicolumn{2}{|l|}{1.474} & \multicolumn{2}{|l|}{1.430} \\
\hline 4 & $\begin{array}{l}\text { Upper } \\
\text { Didessa }\end{array}$ & 1.98 & \multicolumn{3}{|c|}{1.977} & \multicolumn{2}{|l|}{1.537} & \multicolumn{2}{|l|}{1.533} \\
\hline 5 & $\begin{array}{c}\text { Didessa } \\
\text { Main }\end{array}$ & 10.71 & \multicolumn{3}{|c|}{10.632} & 10.016 & & \multicolumn{2}{|l|}{9.609} \\
\hline \multirow{2}{*}{$\begin{array}{l}\text { Sr. } \\
\text { no. }\end{array}$} & \multirow[t]{2}{*}{ River } & \multirow{2}{*}{$\begin{array}{l}\text { 'Natural' (output of SWAT } \\
\text { model) }\end{array}$} & \multicolumn{7}{|c|}{ Annual water consumed under each scenario (BCM) } \\
\hline & & & $\begin{array}{l}\text { Curre } \\
\text { devel }\end{array}$ & oment & $\%$ & $\begin{array}{l}\text { Medium-term future } \\
\text { development }\end{array}$ & $\%$ & $\begin{array}{l}\text { Long-term future } \\
\text { development }\end{array}$ & $\%$ \\
\hline \multicolumn{10}{|c|}{ b. Change (decrease) in annual flow across scenarios } \\
\hline 1 & Anger & 3.31 & 0.07 & & 2.0 & 0.26 & 7.9 & 0.38 & 11.5 \\
\hline 2 & Dabena & 1.22 & 0.001 & & 0.1 & 0.002 & 0.2 & 0.031 & 2.5 \\
\hline 3 & Wama & 1.51 & 0.023 & & 1.5 & 0.036 & 2.4 & 0.080 & 5.30 \\
\hline 4 & $\begin{array}{l}\text { Upper } \\
\text { Didessa }\end{array}$ & 1.98 & 0.003 & & 0.2 & 0.443 & 22.4 & 0.447 & 22.6 \\
\hline 5 & $\begin{array}{l}\text { Didessa } \\
\text { Main }\end{array}$ & 10.71 & 0.078 & & 0.7 & 0.694 & 6.5 & 1.101 & 10.3 \\
\hline
\end{tabular}

The base for estimation of the consumed is taken as the 'natural' flow (SWAT's output)

Table 11 Spatial occurrence of unmet demands across watersheds

\begin{tabular}{|c|c|c|c|c|c|}
\hline \multirow[t]{2}{*}{ Sr. no. } & \multirow[t]{2}{*}{ Watershed/reach name } & \multirow[t]{2}{*}{ Scenarios } & \multicolumn{3}{|c|}{ Volume of water (MCM) } \\
\hline & & & Demand & Supply delivered & Unmet demand \\
\hline \multirow[t]{3}{*}{1} & \multirow[t]{3}{*}{ Anger } & Reference & 55.54 & 50.29 & 5.25 \\
\hline & & Medium-term future & 254.58 & 235.20 & 19.38 \\
\hline & & Long-term future & 450.77 & 410.18 & 40.59 \\
\hline \multirow[t]{3}{*}{2} & \multirow[t]{3}{*}{ Dabena } & Reference & 0.95 & 0.93 & 0.02 \\
\hline & & Medium-term future & 1.81 & 1.81 & 0.00 \\
\hline & & Long-term future & 39.71 & 34.13 & 5.58 \\
\hline \multirow[t]{3}{*}{3} & \multirow[t]{3}{*}{ Wama } & Reference & 8.12 & 7.76 & 0.36 \\
\hline & & Medium-term future & 47.92 & 47.92 & 0.00 \\
\hline & & Long-term future & 165.69 & 165.69 & 0.00 \\
\hline \multirow[t]{3}{*}{4} & \multirow[t]{3}{*}{ Upper Didessa } & Reference & 3.11 & 2.53 & 0.58 \\
\hline & & Medium-term future & 425.49 & 410.45 & 15.04 \\
\hline & & Long-term future & 430.06 & 414.84 & 15.22 \\
\hline \multirow[t]{6}{*}{5} & \multirow[t]{3}{*}{ Didessa Main (some reaches) } & Reference & 7.00 & 6.56 & 0.44 \\
\hline & & Medium-term future & 16.42 & 16.25 & 0.17 \\
\hline & & Long-term future & 113.10 & 112.93 & 0.17 \\
\hline & \multirow[t]{3}{*}{ Total } & Reference & 74.72 & 68.07 & 6.65 \\
\hline & & Medium-term future & 746.22 & 711.624 & 34.59 \\
\hline & & Long-term future & 1199.33 & 1137.77 & 61.56 \\
\hline
\end{tabular}


Fig. 9 Annual unmet demand per demand sites at the end of each scenario period

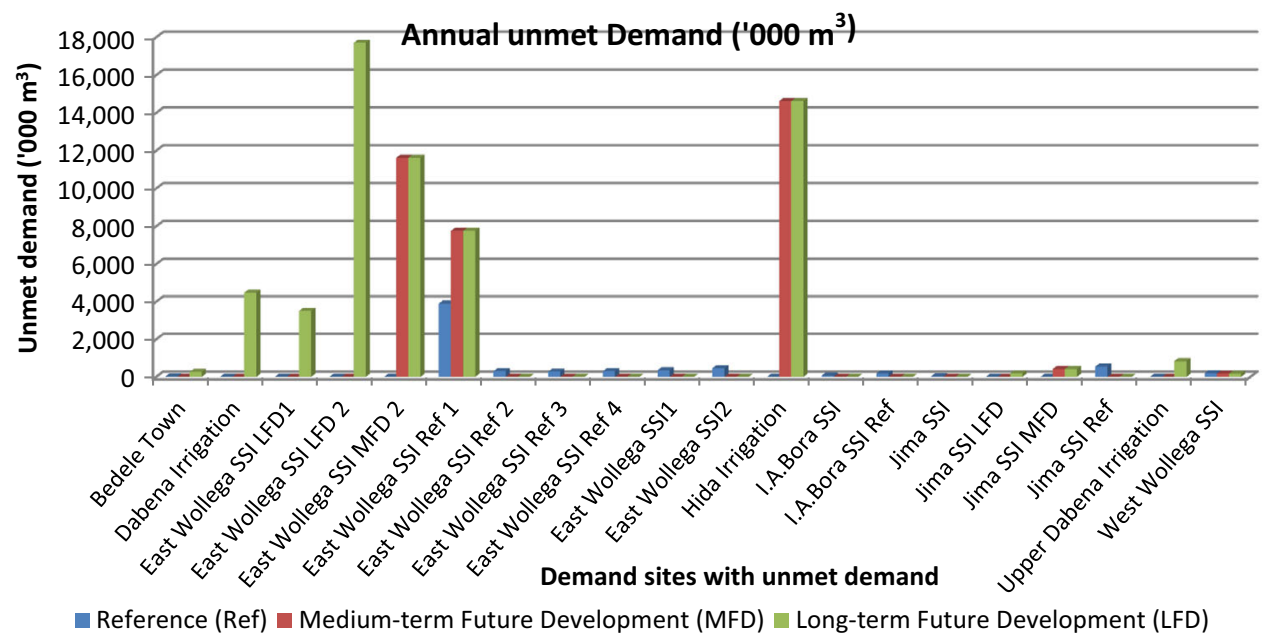

- Reference (Ref) $\square$ Medium-term Future Development (MFD) — Long-term Future Development (LFD)
The output of WEAP shows that during the Reference Scenario period, the water demand of some demand sites were not satisfied. The major demand sites with unmet demand are SSI demand sites in East Wollega Administrative Zone. Of course, there is no sub-basin wide absolute scarcity of water during this scenario. As indicated in the Abbay Basin Integrated Development Master Plan document, the exact location of all SSI schemes is not known; therefore, the shortage might have occurred due to the approximate positioning of the schemes. The second possible cause of the shortage is that for all irrigation demand sites, the crop water requirement was calculated for the highest crop water demand, which might not have been the case in practice. The total annual unmet demand was about $6.65 \mathrm{MCM}$.

During the medium-term future development Scenario, most of the demands are met. Some SSI demand sites and one large scale irrigation demand site have unmet demand. The annual unmet demand during the medium-term future development scenario is $34.59 \mathrm{MCM}$. The total supply delivered is $711.624 \mathrm{MCM}(6.645 \%$ of the total annual streamflow), against a demand of $746.22 \mathrm{MCM}(6.97 \%$ of the total Didessa annual flow).

At the end of the long-term future development scenario, the annual unmet demand in Didessa Sub-basin would reach about $61.56 \mathrm{MCM}$. The annual supply delivered would be about 1137.77 MCM (10.62 \% of the mean annual flow), against a demand of 1199.33 MCM (11.20\% of the annual flow). The demand sites with unmet demand are SSI demand sites in East Wollega, West Wollega and Jima Zones, and medium and large scale irrigation demand sites in Dabena and Upper Didessa Watersheds. Bedele Town Demand Site, which derives its water from Dabena River, is also included among sites with unmet demand.

\section{Temporal occurrence of unmet demands}

Table 12 shows temporal (monthly) occurrence of unmet demand under the three development scenarios.

The above table shows that at the end of the long-term future development scenario (2050), demand will be fully met during the months of June-October only. This is typically the main rainy season in the study area. During the remaining seasons, there are varying amount of unmet demand.

\section{Water shortage hotspots}

Similar to the characteristics of rainfall distribution, there is variability in the spatial and temporal distribution of streamflow across the sub-basin. The water shortage hotspots are identified depending on the extent to which the surface water resource in the corresponding catchment is capable of meeting the demand of demand sites and the instream flow requirements.

Table 12 Temporal occurrence of unmet demand across watersheds (MCM)

\begin{tabular}{|c|c|c|c|c|c|c|c|c|c|c|c|c|c|}
\hline \multirow[t]{2}{*}{ Scenario } & \multicolumn{12}{|l|}{ Month } & \multirow[t]{2}{*}{ Sum } \\
\hline & Jan & Feb & Mar & Apr & May & Jun & Jul & Aug & Sep & Oct & Nov & Dec & \\
\hline Long-term future development & 16.21 & 14.75 & 10.48 & 7.46 & 3.92 & 0 & 0 & 0 & 0 & 0 & 0.10 & 8.65 & 61.56 \\
\hline Medium-term future development & 10.90 & 9.37 & 4.09 & 1.49 & 0 & 0 & 0 & 0 & 0 & 0 & 0.10 & 8.65 & 34.59 \\
\hline Reference & 1.87 & 2.02 & 0.09 & 0.07 & 0 & 0 & 0 & 0 & 0 & 0 & 0 & 2.60 & 6.65 \\
\hline
\end{tabular}


With respect to watersheds, the water demand in Anger Watershed is the most unmet. All the demands in Dabena Watershed, including Bedele Town Demand Site, are unmet at the end of the long-term future development scenario. The shortage of water to meet the water demand of Bedele Town water supply is very critical if alternative water source is not available. The annual water demand of Bedele water supply demand site is unmet by about $2,62,000 \mathrm{~m}^{3}$.

Similarly, environmental water needs are not met in Dabena Watershed. To fully meet the annual Instream Flow Requirement, a deficit of $21 \mathrm{MCM}$ of water is observed. Temporally, shortage of water is observed during the months of November-March.

In the other watersheds too, there are patch pockets where demands are not fully met. The demand of most SSI demand sites in East Wollega, West Wollega, I/A/Bora and Jima zones (Anger, Wama and Upper Didessa Watersheds), and that of Hida Irrigation (located in Upper Didessa Watershed) are unmet during the medium term future development scenario (for some of them) and the long-term future development scenario (for most of them). The instream flow requirements are met in all watersheds except Dabena. Regarding the SSI demand sites, the shortage of water might have occurred due to the possible reason of locating some of the sites approximately.

\section{Summary and conclusions}

\section{Summary}

The main objective of the study was to assess the possible impacts of upstream surface water abstraction in Didessa Sub-basin on downstream water availability and environmental flows. The water evaluation and planning (WEAP) Tool was used to evaluate the impacts. The three major categories of demand sites encompassed in the analysis were the irrigation demand sites, domestic (urban) water demand sites and hydroelectric power demand site. The annual activity levels for the demand sites were collected primarily from the Abbay Basin integrated development master plan of 1998. Besides, recent data on irrigation development and water supply have been collected from the irrigation development and water supply sectors of the government.

During the model setup, all demand sites, including the environmental flows, were assigned the same priority. The basic reason behind is that the environment is legitimate user of water and, therefore, should be allocated its fair share of the resource.

The agricultural (irrigation) water demand (crop water requirement) was estimated using CROPWAT 8.0, a program developed by the Food and Agricultural Organization of the United Nations. To be on the safest side, the highest crop water demand was considered. At the end of the master plan period, the total irrigation annual activity level will reach 189,780 ha, and the corresponding annual water requirement will be 1.162 BCM. The supply requirement for the two urban areas, Nekemte and Bedele towns, will be 19.612 MCM per year.

Similarly, the environmental flows (instream flow requirement) was estimated using the indicators of hydrologic alteration (IHA), a program developed by The nature conservancy. At the outlet of Didessa River, the total annual IFR of about 5.46 BCM is fully met at the end of the long-term future development scenario (end of the master plan implementation period).

The analysis has shown that, at the end of the master plan implementation period (2050), the reduction in the mean annual flow of Didessa River due to the development will be about $10.3 \%$ of the total. Similarly, the reduction in the annual flow of the major tributaries will be $11.5,2.5,5.3$ and $22.6 \%$, respectively, for Anger, Dabena, Wama and Upper Didessa rivers. Watershed wise, Dabena is the only one with unmet instream flow requirement. Despite the non-existence of universal shortage of water in Didessa Sub-basin, there are water shortage hotspots in all watersheds. The temporal occurrence of these shortages and the unmet IFR are during the months of November-March. This is the typical dry season in the area, and it is the season with the highest irrigation water requirement.

\section{Conclusions}

As part and parcel of the endeavors to assess the sustainability and environmental integrity of the existing and planned water resources development in Didessa Subbasin, the water evaluation and planning (WEAP) model has shown a clue on what would possibly happen after the planned water resources development is fully implemented. It has been shown that at the end of the long-term future development scenario period (2050), some watersheds in Didessa Sub-basin will fall under a water shortage situation.

Overall, the impact of the existing and planned water resources development on delivery of instream flow requirements and downstream water availability is minimal. By the end of 2050, the reduction in the total annual flow of Didessa River due to the existing and planned water resources development would be about 1.101 BCM (10.3\% of the total annual flow). A watershed which should be rendered special focus is Dabena Watershed, where the water demand of all demand sites, including the IFR, would not be met at the end of the long-term future 
development scenario. If the water resources development plans in this watershed need to be implemented without any major detrimental effect on the environment, it might be necessary to make arrangements to provide storage facilities that would minimize the ill-effects of the development endeavors.

Regarding the irrigation development demand sites whose demands are not met, the watersheds where they are situated are, generally, not in a water shortage situation. Therefore, the problem might be resolved by locating the schemes based on proper feasibility analyses.

Moreover, this study demonstrates that the problems associated with lack of information on water resources, especially recorded hydrological data, can be tackled by supplementing the existing data from few conventional gauging stations with the outputs of hydrological models like SWAT, and using in water allocation models.

This analysis was made based on data and information gathered from the master plan project document, which is crude by its nature, as it was prepared for a large river basin, where there is the possibility of overlooking things that were happening at sub-basin or small watershed scale. Hence, some of the parameters that were input in the WEAP model were fixed based on assumptions. Nonetheless, the results of this study are indicative of what may happen and what need to be done; and the data generated here might be a springboard for further study on issues related to sustainable water resources planning and development in the sub-basin.

The study was conducted on the basis of the Abbay Basin integrated development master plan, where groundwater was not considered as an alternative supply source, in order to evaluate the impact of the existing and planned development on instream and downstream water availability. It was considered that the assumptions on which the master plan study was based will prevail, as this is one possible scenario. Therefore, it is recommended that further study addressing potential climate and land use/cover change scenarios, and groundwater resources as alternative supply sources be conducted in the future. Besides, it is recommended that site specific crop water demand be estimated based on surveys to perform more refined water resources allocation modeling.

Acknowledgments The authors are grateful to the editor of the journal and the anonymous reviewer/s for their relevant and valuable comments on earlier version of the manuscript due to which the contents of this paper have been enriched.

\section{References}

Alemayehu T, McCartney M, Kebede S (2010) The water resource implications of planned development in the Lake Tana catchment. Ethiopia Ecohydrol Hydrol 10(2-4):211-222

Arranz R, McCartney M (2007) Application of the water evaluation and planning (WEAP) model to assess future water demands and resources in the olifants catchment, South Africa. IWMI Working Paper 116. Colombo, Sri Lanka: Internation Water Management Institute

FAO (2012) Coping with water scarcity-An action framework for agriculture and food security. Food and Agricultural Organization of The United Nations, Rome

Hughes DA, Hannart P (2003) A desktop model used to provide an initial estimate of the ecological instream flow requirements of rivers in South Africa. J Hydrol 270:167-181

Leite JC, Hadad GD, Doorn JH, Kaplan GN (2000) A scenario construction process. Requirements Eng 5:38-61

McCartney MP, Girma MM (2012) Evaluating the downstream implications of planned water resource development in the Ethiopian portion of the Blue Nile River. Water Int 37(4):362-379. doi:10.1080/02508060.2012.706384

Mehta VK, Haden VR, Joyce BA, Purkey DR, Jackson LE (2013) Irrigation demand and supply, given projections of climate and land-use change, in Yolo County, California. Agric Water Manag 117:70-82

Mounir ZM, Ma CM, Amadou I (2011) Application of water evaluation and planning (WEAP): a model to assess future water demands in the Niger River (In Niger Republic). Modern Appl Sci 5(1):38-49

MWR (1999) Abbay River Basin master plan project-phase 3main report. Ministry of Water Resources, Addis Ababa

Richter BD, Baumgartner JV, Wigington R (1997) How much water does a river need? Freshw Biol 37:231-249

SEI (2011) WEAP water evaluation and planning system user guide. Stockholm Environ Institute, Somerville

Smakhtin VU, Shilpakar RL, Hughes DA (2006) Hydrology-based assessment of environmental flows: an example from Nepal. Hydrol Sci 2:207-222

Tena BA, Srinivasa Rao GVR, Abbulu Y (2015) Assessment of spatio-temporal occurrence of water resources in Didessa Subbasin, West Ethiopia. IJCSEIERD 5:105-120

The Nature Conservancy (2009) Indicators of hydrologic alteration version 7.1 User's Manual. User's Manual. The Nature Conservancy

Weng S, Huang G, Li Y (2010) An integrated scenario-based multicriteria decision support system for water resources management and planning - a case study in the Haihe River Basin. Expert Syst Appl 37:8242-8254

WHO (2003) Right to water. Retrieved from Office of the United Nations High Commissioner for Human Rights: http://www2. ohchr.org/english/issues/water/docs/Right_to_Water.pdf

WIKIPEDIA (2015) Scenario_analysis. Retrieved from WIKIPEDIA The Free Encyclopedia: http://en.wikipedia.org/wiki/Scenario_ analysis

Yates D, Sieber J, Purkey D, Lee (2005) WEAP21-a demand-, priority-, and preference-driven water planning model-part 1: model characterisitics. Int Water Res Assoc 30(4):487-500 